\title{
BLACK IS BLACK: IDENTIDAD AFROAMERICANA, BARACK OBAMA Y LAS POLÍTICAS DE LA IMAGEN EN LA WEB 2.0
}

\author{
LUIS VIVES-FERRÁNDIZ \\ Universitat Jaume I
}

RESUMEN: El presente artículo estudia el uso estratégico de las redes sociales por parte de Barack Obama para reforzar su identidad afroamericana y su blackness. Obama, desde la campaña electoral de 2008, ha sido criticado por no ser representativo de la población negra. Sin embargo, tras su victoria electoral, Obama y su equipo han desarrollado una estrategia basada en el uso de las redes sociales para relacionar la imagen de Obama con los mitos y leyendas de las luchas por los derechos civiles de los años sesenta. Así, la identidad se convierte en algo customizable, la llamada post-blackness.

Palabras clave: Barack Obama, web 2.0, identidad afroamericana, postblackness, postfotografía.

ABSTRACT: The aim of the present paper is to analyse the use of the social media by Barack Obama to strengthten his African-American identity and his blackness. Since the presidential campaign of 2008, Obama has been criticized for not being black enough. However, after his presidential win, Barack Obama and his team had pursued a strategy based on the use of social media to link the image of Obama to the myths and legends of the civil rights movement of the 60's. Then, identity is seen as something malleable, the so-called post-blackness.

Keywords: Barack Obama, web 2.0, African American identity, postblackness, post-photography. 


\section{Cultura mediática, Web 2.0 y Postfotografía}

$\mathrm{E}_{\mathrm{p}}^{\mathrm{n}}$ las últimas décadas del siglo $\mathrm{xx}$, la cultura mediática formada por los productos de la televisión, la radio, la música o el cine, entre otros, ha proporcionado una cantidad ingente de imágenes, materiales, símbolos, mitos o fuentes a partir de los cuales forjar identidades y visiones políticas del mundo. Por medio de la imagen, la cultura de los medios proporciona recursos para forjar identidades en un terreno complejo en el que los espectadores son invitados a identificarse con ideologías, posturas y representaciones sociales dominantes, a veces con resistencia, a veces con sumisión. ${ }^{1}$

La cultura mediática ha visto incrementado, en los últimos años, la cantidad de productos que se engloban bajo este término ya que se debe añadir el no menos ingente campo de Internet y la llamada web 2.0, ámbitos que proporcionan nuevos materiales basados en la imagen con los que también forjar identidades. A partir de 2003 comienza lo que se ha denominado la era de la web 2.0 o web participativa, ${ }^{2}$ un término que alude a un nuevo modelo de negocio en Internet y que define una serie de desarrollos técnicos, económicos y sociales que han determinado un nuevo universo mediático. Páginas como Facebook, Twitter, YouTube, Vimeo o Flickr son el paradigma de la web 2.0 ya que permiten a los usuarios gestionar sus propios contenidos y mantener una comunicación instantánea y global que determina su sociabilidad.

Paralelamente, el desarrollo de la imagen digital ha abierto un campo todavía inexplorado de la cultura mediática. En el campo de la fotografía, el advenimiento de lo digital generó debates que todavía siguen abiertos acerca de la ontología de la imagen fotográfica. Los píxeles han cuestionado el eidos de la fotografía de un modo tal que ha llevado a diversos autores a buscar un nuevo término con el que bautizar a las fotografías digitales: ${ }^{3}$ Mitchell ya habló en 1992 de la post-photographic era, ${ }^{4}$ mientras que Fontcuberta también utiliza el término postfotografía para designar al nuevo caudal de imágenes que desde cámaras, teléfonos móviles o tabletas se realizan a diario y que necesitan ser definidas. ${ }^{5}$

Las instituciones de poder no han permanecido ajenas a estos dos procesos ya que han explotado las posibilidades de la web 2.0 y la fotografía digital

1. Douglas Kellner, Cultura mediática. Estudios culturales, identidad y política entre lo moderno y lo posmoderno, Akal, Madrid, 2012.

2. T. O'REILly, What is web 2.0. Design patterns and business models for the next generation of software, 2005: http://oreilly.com/web2/archive/what-is-web-20.html [10 de julio de 2013]. Para su uso por parte de artistas es imprescindible JuAn Martín Prada, Prácticas artísticas en internet en la época de las redes sociales, Akal, Madrid, 2012 y Margarida Rodríguez IbÁÑez, Cómo la red ha cambiado el arte, Trea, Gijón, 2012.

3. DAvid Green, ¿Qué ha sido de la fotografía?, Gustavo Gili, Barcelona, 2007.

4. W. J. T. MitchelL, The reconfigured eye: visual truth in the post-photographic era, MIT, Cambridge, 1992.

5. Joan Fontcuberta, La cámara de Pandora. La fotografía después de la fotografía, Gustavo Gili, Barcelona, 2012. Véanse también las reflexiones sobre el tema en MARTIN Lister (comp.), La imagen fotográfica en la cultura digital, Paidós, Barcelona,1997. 
en beneficio propio con la intención de promover valores, ideas y visiones políticas que moldean viejas y nuevas identidades. Hablar de redes sociales e instituciones de poder no puede hacerse sin recordar a Barack Obama en su carrera a la Casa Blanca en las elecciones presidenciales de 2008, pues el entonces senador Obama se distinguió en la campaña electoral por utilizar las redes sociales con el fin de movilizar al electorado estadounidense como nunca antes se había hecho. ${ }^{6}$ Tras ganar las elecciones, la complicidad del equipo de Obama con las redes sociales fue en aumento y se fueron creando perfiles institucionales en Facebook, ${ }^{7}$ Twitter, ${ }^{8}$ Flickr, ${ }^{9}$ Instagram, ${ }^{10}$ YouTube, ${ }^{11}$ Vimeo, ${ }^{12}$ Ustream ${ }^{13}$ o Google $+{ }^{14}$ que contienen, todavía hoy en día, perfiles de Barack Obama y la Casa Blanca en los que se difunden las actividades del presidente, los encuentros con distintos mandatarios, los viajes oficiales, escenas familiares, retratos oficiales y un largo etcétera en función de las particularidades de la red social.

De entre todos estos perfiles, la cuenta oficial de la Casa Blanca en Flickr es uno de los recursos más interesantes ya que constituye un verdadero archivo visual del sueño americano, del American way of life, mostrando sus mitos, sus valores, sus creencias y su historia. ${ }^{15}$ A fecha de hoy, se muestran casi 5000 imágenes del presidente y su equipo que dan buena cuenta, no solo de su trabajo diario, sino de la ideología y los mitos de la cultura americana. El espacio que la Casa Blanca dispone en Flickr es uno de esos nuevos espacios de la cultura mediática en los que se forjan identidades a partir de la imagen.

\section{IDENTIDAD AFROAMERICANA: LA POST-BLACKNESS Y BARACK OBAMA}

Cuando Barack Obama ganó las elecciones presidenciales en noviembre de 2008, se escribió un nuevo capítulo en la historia de los derechos civiles. Por primera vez, un hombre negro se convertía en presidente de los Estados Unidos de América, país que abanderó la libertad y la democracia desde su independencia pero que, paradójicamente, mantuvo leyes segregacionistas hasta bien avanzado el siglo xx que impidieron a los negros disfrutar de los

6. Para los pormenores de este uso véase A. Soní-Soto, «Mitos y símbolos en la campaña de Barack Obama», Palabra Clave, 14 (2011), pp. 76-82. 2013].

7. https://www.facebook.com/WhiteHouse y https://www.facebook.com/barackobama [1 de julio de

8. https://twitter.com/BarackObama y https://twitter.com/whitehouse [1 de julio de 2013].

9. http://www.flickr.com/photos/whitehouse/ [1 de julio de 2013].

10. http://web.stagram.com/n/barackobama [concebido para la campaña electoral de 2012, consultado el 1 de julio de 2013]

11. http://www.youtube.com/user/whitehouse [1 de julio de 2013].

12. https://vimeo.com/whitehousevideos [1 de julio de 2013].

13. http://www.ustream.tv/barackobama [1 de julio de 2013].

14. https://plus.google.com/+whitehouse/posts [1 de julio de 2013].

15. Luis Vives-FerRÁndiz SÁNCHEZ, «Yes, we Flickr! Imágenes del poder en la era de la postfotografía», en Víctor Mínguez (ed.), Las artes y la arquitectura del poder, uji, Castellón, 2013, pp. 501-516. 
mismos derechos que sus conciudadanos blancos. Sin embargo, por extraño que pueda parecer, durante la campaña electoral que precedió a las elecciones se abrieron intensos debates que cuestionaban la idoneidad de Obama para acaparar el voto de la comunidad negra pues el candidato no era considerado, por algunos, el mejor representante de la blackness, ${ }^{16}$ de la identidad cultural específica de la población de raza negra basada y conformada a partir de un pasado de esclavitud y de segregación. ${ }^{17}$

El debate consistió en dirimir si Obama era lo suficientemente «negro» como para solicitar y aglutinar el voto de los afroamericanos en la campaña electoral que le llevó a la presidencia. Escritores, periodistas o columnistas de color mostraron públicamente su rechazo a que Obama encarnase los valores de la población negra, como Stanley Crouch en New York Daily News ${ }^{18}$ quien aseguraba que salvo por el color de la piel, Barack Obama no tenía ninguna relación con la mayoría de afroamericanos descendientes de esclavos, o Debra Dickinson, que veía en Obama una figura que habría desplazado la verdadera identidad negra y que encarnaba una visión higienizada de los negros con el que los votantes de cualquier color podrían empatizar sin ningún sentimiento de culpa o miedo. ${ }^{19}$ Otros intelectuales calificaron de absurdo el debate ya que cuestionar el grado de proximidad de Obama con la comunidad negra era algo anacrónico o, incluso, peligroso. ${ }^{20}$

Sin embargo, no es menos cierto que Barack Obama ha tenido dificultades para mostrar su proximidad con la identidad cultural afroamericana pues su biografía contiene detalles y vivencias que no hacen de él un ejemplo de blackness: Obama nace en Hawái, hijo de una mujer blanca de Kansas y de un padre negro originario de Kenia (la ascendencia africana es un tema que sí que lo podría emparentar con la identidad afroamericana) y que vive durante varios años en Indonesia. ${ }^{21}$ Su biografía y su identidad no contienen, a priori, ninguno de los aspectos con los que la comunidad negra podría identificarse ya que no ha vivido en primera persona los problemas de segregación que se

16. RoN WALters, «Barack Obama and the politics of blackness», Journal of Black Studies, 38 (2007), pp. 7-29. Del mismo modo que se estudian los perfiles de la identidad negra, se han realizado estudios sobre la identidad de los blancos, la llamada whiteness. Véase Ruth Frankenberg (ed.), Displacing whiteness. Essays in social and cultural criticism, Duke University Press, Duke, 1997.

17. Para la historia de la segregación racial de los negros en los Estados Unidos véase DAVID R. Roediger, How race survived the US history. From settlement and slavery to the Obama phenomenon, Verso, Nueva York, 2008.

18. http://www.nydailynews.com/archives/opinions/obama-isn-black-race-article-1.585922 [15 de junio de 2013].

19. http://www.salon.com/2007/01/22/obama_161/ [15 de junio de 2013].

20. Algunas de estas respuestas en WALters, Barack Obama, p. 10.

21. Hasta hace muy pocos años se consideraba que una persona se englobaba dentro de la blackness si tenía algún ascendente africano. Era lo que se definió como la one drop rule, la regla que establecía que una sola gota de sangre negra era suficiente para considerar a una persona como negra. El origen de esta definición se sitúa a finales del siglo xıx y sirvió para promover políticas segregacionistas. Paradójicamente, la one drop rule solo se aplica en los Estados Unidos, lo que da una idea bien clara de cómo la identidad cultural y racial es algo construido y negociado. Sobre este punto, véase F. JAmEs DAvis, Who is black? One nation's definition, The Pennsylvania State University, Pennsylvania, 2005. 
asocian con el gueto ni participó en las luchas por los derechos civiles que se desarrollaron en los Estados Unidos en los años sesenta y setenta del pasado siglo.

Obama, de este modo, se vio obligado a reforzar, por medio de distintas estrategias, su pertenencia a la identidad cultural negra, tanto durante la campaña electoral del año 2008 como durante sus dos mandatos presidenciales. Obama moldea su identidad afroamericana gracias a las posibilidades de la nueva cultura mediática de la web 2.0 ya que va a vincular su figura e imagen con aquellas personas o acontecimientos que marcaron las luchas por los derechos civiles de los afroamericanos.

En el fondo de este debate subyace la cuestión de cuáles son los límites de la identidad negra, cuáles son los rasgos que definen a la blackness y que permiten dirimir si una persona es representativa de esos rasgos o no. En los últimos años se ha acuñado un término que problematiza la cuestión de la identidad afroamericana al mismo tiempo que abre un nuevo campo de posibilidades en el estudio de las identidades y la cultura mediática: la post-blackness. ${ }^{22} \mathrm{El}$ concepto de post-blackness se refiere a la habilidad de alguien que está enraizado en sus orígenes negros pero no limitado ni restringido por ellos. El término desafía la idea de una identidad negra fija, estable e inmóvil y abre la puerta a una identidad más maleable, funcional y flexible. Para Touré, vivimos en una era definida por la post-blackness, lo que significa que las definiciones y límites de la blackness se están extendiendo hacia millones de posibilidades pues cada persona negra puede ser una identidad representativa de la blackness. No significa abandonar la identidad afroamericana sino ampliar la visión que se tiene de ella. ${ }^{23}$

El origen del término post-blackness se sitúa en el campo de arte y fue acuñado por Thelma Golden, curator del Studio Museum de Harlem, con motivo de la exposición Freestyle celebrada en el citado museo en el año 2001. Los artistas que formaron parte de la exposición rechazaron ser calificados como black artists ya que consideraban que ser etiquetados como negros limitaba la percepción y alcance de su trabajo. Artistas como Jean Michel Basquiat, Kara Walker o Kehinde Wiley trabaron temas relacionados con el racismo pero de una manera novedosa, irónica, cómica y crítica, tomando distancia respecto a los temas raciales. La exposición hablaba, de este modo, del post-black art, de un arte que no es exclusivo de los negros, hecho por negros y para ser consumido por negros, sino que es un arte compartido por toda la sociedad. ${ }^{24}$ Con la exposición Freestyle, la identidad negra comenzaba a ser revisitada y se asumía que podría ser moldeada en función de las circunstancias, el tiempo y el lugar. Definir quién es negro comenzó a ser una pregunta difícil de responder.

22. TOURÉ, Who's afraid of post-blackness? What means to be black now, Free Press, Nueva York, 2012

23. Ibidem, 12 .

24. Ibidem, 31-32. 
Al hilo de esta nueva era en la percepción de la identidad afroamericana no han faltado debates sobre si, tras la elección de Barack Obama, se ha iniciado una era posracial en la que la raza ya no constituiría un elemento diferenciador a nivel social o político. Para Mitchell, la elección de Obama es un momento remarcable que desafía las cuestiones identitarias que hasta hace poco asumíamos como inmutables, aunque puntualiza la necesidad de mantener ciertas diferencias raciales. Para este autor, es a través de la raza como percibimos la otredad y las diferencias con otros grupos. La heterogeneidad racial es lo que hace que el racismo sea visible y el mejor instrumento para combatir contra él, por lo que luchar por una sociedad color blind no es deseable ni un objetivo que se deba alcanzar. ${ }^{25}$

Para otros autores, la elección de Obama no ha abierto las puertas a ninguna era posracial ya que el aislamiento y separación de los afroamericanos se mantiene de facto. ${ }^{26}$ Además, la realidad de la raza y la diversidad étnica de los Estados Unidos influye de manera poderosa en el resultado de unas elecciones presidenciales. Es lo que se ha definido como la «diversidad segregada», un concepto que se refiere a la diversidad de identidades y etnias que se da en los Estados Unidos en función de su segregación. Es decir, que el hecho de que los distintos grupos estén segregados y diferenciados es lo que posibilita que unos asimilen o absorban a otros y consigan crear mayorías que puedan dar la victoria en unas elecciones. ${ }^{27}$

\section{LOS MITOS DE LA BLACKNESS Y BARACK OBAMA: DE LA CAMPAÑA ELECTORAL A la plusvalía de la postfotografía}

La campaña de Obama para las elecciones de 2008 se basó en hacer uso de la post-blackness mostrando una blackness funcional, customizable, ambivalente y moldeable que no se dirige en exclusiva a empatizar con el voto negro, sino a plantear una política inclusiva en la que las cuestiones que preocupan a la comunidad afroamericana y los blancos se vean reflejadas.

Obama protagonizó durante su primera campaña electoral una serie de actos deliberados que buscaban conectar con el legado de la lucha por los derechos civiles que le permitían reforzar esa blackness funcional. Uno de los más significativos tuvo lugar el 11 de marzo de 2007 cuando Obama pronunció un

25. W. J. T. MitchelL, Seeing through race, Harvard University Press, Cambridge, 2012.

26. Melvin E. Thomas, Cedric Herring, Hayward Derrick Horton, «Racial differences in the perception of racial equality in the Obama era», en DONALD CUNNINGEN y MARINO A. Bruce (eds.), Race in the age of Obama, Emerald, Bingley, 2010, pp. 177-192. Véanse también las reflexiones en torno a la raza $y$ el ascenso de Barack Obama en GERALD EARLY, «The two words of race revisited: a meditation of race in the age of Obama», Daedalus 140 (2011), pp. 11-27.

27. John Sibley ButLER, "The managment of social theory: Obama and the American presidency in the age of segregated diversity», en CUnNingen y BRUCE, Race, pp. 127-147. A lo largo de la historia de los Estados Unidos, tan solo Kennedy y Obama han sido presidentes que no han formado parte del grupo WASP. Todos los grupos sociales y étnicos se han acomodado, en diferentes grados, al poder de los WASP. 
discurso en la Brown Chapel de Selma, Alabama, una iglesia metodista que en 1965 fue el punto de partida de una marcha pacífica por los derechos civiles de la población negra que debía llegar hasta Montgomery, Alabama. El lunes 7 de marzo de 1965, 600 manifestantes encabezados por los activistas John Lewis y Hosea Williams que trataban de alcanzar pacíficamente el edificio del capitolio de Montgomery fueron brutalmente disueltos con gases antidisturbios y golpeados por la policía con porras, un infame día que ha pasado a la historia con el nombre de Bloody sunday. Los periódicos de toda la nación mostraron fotografías en las que se enfatizaba la desmedida actuación de las fuerzas estatales, provistos de máscaras antigás y armados con porras frente a la resistencia pasiva y pacífica de los afroamericanos, imágenes que tuvieron un fuerte impacto en la opinión pública norteamericana. ${ }^{28}$ Brown Chapel es una lugar icónico para la historia contemporánea de los Estados Unidos y, especialmente, para la historia de los derechos civiles pues, poco después, el presidente Lyndon B. Johnson firmó la Voting Rights Act, el 6 de agosto de 1965, por la que se ponía fin a la discriminación que sufría la población negra para poder votar.

La elección de Selma para pronunciar el discurso fue una decisión plenamente política que buscaba identificar a Barack Obama con una de los lugares de la memoria de la identidad afroamericana en los Estados Unidos. Que un candidato presidencial negro pronuncie un discurso en la Brown Chapel es toda una declaración de intenciones acerca de qué mitos y temas se quieren relacionar con Barack Obama pues, sin ambos acontecimientos, la marcha y la firma de la ley, su candidatura no hubiese sido posible.

Aunque Obama sea negro, su política no va encaminada exclusivamente a resolver los problemas raciales que siguen afectando a los afroamericanos, sino que aboga por una política inclusiva en la que los blancos también se encuentran identificados. En este sentido, el discurso sobre la raza que Obama pronunció en 2008, titulado A more perfect union y considerado hasta la fecha la declaración oficial más importante sobre el tema que ha realizado un presidente de los Estados Unidos, no se centra en los problemas de los negros sino que apela a la unión entre todos. ${ }^{29}$ Obama recuperó para su discurso las palabras que encabezan la Constitución de 1787 para hablar de los desafíos raciales entre blancos y negros en la América contemporánea con la intención de conseguir a more perfect unión, ${ }^{30}$ una unión cada vez más perfecta entre los distintos grupos que conforman la sociedad americana y que sea capaz de

28. Martin A. Berger, Seeing through race. A reinterpretation of civil rights photography, University of California Press, Berkeley - Los Angeles, 2011, pp. 1-4.

29. http://obamaspeeches.com/E05-Barack-Obama-A-More-Perfect-Union-the-Race-SpeechPhiladelphia-PA-March-18-2008.htm [15 de julio de 2013].

30. "We the people, in order to form a more perfect union» es como empieza tanto el discurso como la constitución de 1787. Obama cita el pasado para enraizar su política y lanzar un discurso de futuro basado en la esperanza. Sobre estas política véase BARAск ОвамA: The audacity of Hope. Thoughts on reclaiming the American dream, Crown Publishers, Nueva york, 2006; D. F. Atwater: «Senator Barack Obama: the rhetoric of Hope and the American dream,» Journal of Black Studies, 38 (2007), pp. 121-129; D. CLAYTON: «The audacity of hope», Journal of Black Studies, 38 (2007), pp. 51-63. 
afrontar los graves problemas que afectan a su país. En su discurso, Obama aboga por respetar las diferencias étnicas y raciales pero exhorta a trabajar juntos para conseguir una América mejor. La unión no fue perfecta en 1787 ni lo ha sido en los últimos años, pero es la obligación de los americanos de hoy en día trabajar juntos para lograr que la perfección sea una realidad cada vez más tangible. La cuestión no es levantar muros entre las diferentes etnias y razas, sino romper esos límites en pos de una actuación común entre todos los ciudadanos. El futuro de América, para Obama, está en la cooperación. De ahí que un discurso sobre la raza no se limitase a tratar los problemas raciales sino a buscar el entendimiento entre todos.

Tras la victoria en las elecciones de 2008, ya como presidente, Obama continuó con esa estrategia que busca enlazar su figura con los mitos de la blackness, aprovechando las posibilidades de la cultura mediática e internet para moldear su identidad afroamericana. La mitología que han conformado las luchas por los derechos civiles de la población negra se actualizan en Barack Obama y en las políticas de la imagen en la era de la web 2.0.

Susan Buck-Morss ha analizado la capacidad de empoderizar que tiene la imagen de Barack Obama, pues está cargada de una energía política que se descarga en el momento de su visualización. Hoy en día, la política se hace visible por medio de imágenes y es gracias a la imagen, a su reproducción y visibilidad digital, lo que posibilita la difusión de ideas y valores políticos. ${ }^{31}$ Lo que distingue a los nuevos políticos es el uso y apropiación de los nuevos canales de comunicación que brinda internet para mostrar sus propios mensajes, dibujando perfiles más amplios en las relaciones entre el poder y la cultura mediática. Las fotografías digitales que pueblan la cuenta en Flickr de la Casa Blanca son agentes activos capaces de introducir e irradiar nuevos valores en el mundo que enlazan con el subconsciente político de los observadores. Ahí reside la plusvalía de la imagen de Obama y su difusión en Flickr, pues la tecnología digital posibilita que imágenes cargadas de sentido político y enraizadas en la memoria colectiva lleguen a un número cada vez mayor de espectadores y se magnifique su poder político. Las fotografías de Obama con los mitos de la blackness tienen la plusvalía de generar nuevos sentidos en los espectadores, de relacionar a Obama con los grandes personajes que han moldeado la identidad afroamericana.

Uno de los primeros actos que Obama protagonizó ya como presidente, y en relación con las luchas por los derechos civiles de los afroamericanos, tuvo lugar en julio de 2011 cuando el Norman Rockwell Museum prestó para ser expuesto en la Casa Blanca la pintura The problem we all live with, un lienzo pintado por Norman Rockwell en 1964 que reflejaba las tensiones raciales que

31. Susan Buck-Morss, «Obama and the image», en Sunil Manghani (ed.), Images: critical and primary sources. Volume 4. Image cultures, Bloomsbury Academic, Londres, 2013, pp. 109-127. Buck-Morss emplea el término inglés empower para referirse a la carga de poder que tiene la imagen de Obama. La Real Academia Española admite el término «empoderizar» como traducción del término. 
desafió una niña de Nueva Orleans para poder asistir a la escuela a comienzos de los años sesenta. La ilustración fue concebida para la revista Look y en ella se muestra a Ruby Bridges en su camino a la escuela escoltada por cuatro us Marshals. La América idealizada que Norman Rockwell había reflejado en sus obras previas (especialmente las que aparecían en el Saturday Evening Post) abre paso a una crítica apasionada de la cara más oscura del sueño americano y muestra una faceta poco resaltada del pintor: su conciencia social y su apoyo a la lucha por los derechos civiles. ${ }^{32}$ El número de la revista Look en la que se encontraba la ilustración, el correspondiente a enero de 1964, estaba dedicado a analizar como vivían los estadounidenses y en su interior, a doble página, se encontraba la imagen de Ruby en su camino a la William Frantz Public School de Nueva Orleans: Ruby era la única niña negra que asistía a una escuela de blancos tras las leyes que habían puesto fin a la segregación racial en la educación americana. Para la realización de la pintura, Rockwell contó con los testimonios de Robert Coles, psiquiatra de la escuela de Ruby, y del escritor John Steinbeck, testigo de unos acontecimientos que reflejó en su libro Travels with Charley. Rockwell aprovecha un número dedicado a la vida típica americana para mostrar una imagen que despierta las conciencias pues el «problema» del que habla es el rechazo racista de los blancos a la integración. ${ }^{33}$

La presencia del cuadro de Rockwell en la Casa Blanca, junto a Obama y la misma Ruby Bridges [Fig. 1], y su difusión a través de las fotografías de Flickr, plantea la actualidad de las luchas por los derechos civiles y el papel de Obama en esa actualización. ${ }^{34}$

En virtud de esa blackness funcional o post-blackness, la fotografía de Obama junto a Ruby Bridges y el cuadro de Rockwell interpela a nuestro presente y plantea cuestiones abiertas sobre la actualidad del racismo. Un vídeo colgado en la cuenta oficial de la Casa Blanca en YouTube muestra a Obama junto a Ruby Bridges y los responsables del Rockwell Museum. Obama se dirige a Ruby y le hace saber que gracias a ella, él puede estar en la presidencia de la Casa Blanca. ${ }^{35}$ Aunque Obama ha vivido una época de tensiones raciales diferentes y su percepción de la blackness sea distinta a la que pueda tener Ruby Bridges, la presencia de la imagen de Rockwell en la fotografía actualiza la realidad del «problema». La presidencia de Obama es consecuencia de las luchas que refleja la pintura de Rockwell y otorgarles visibilidad en el espacio infinito de la web 2.0 posibilita superponer sentidos y valores relacionados con la lucha por

32. V. Gallagher y K. Zagacki, «Visibility and rhetoric: the power of visual images in Norman Rockwell's depictions of civil rights», Quarterly Journal of Speech, 91 (2005), pp. 175-200.

33. En 1954, el caso Brown vs. Board of Education of Topeka puso fin a la segregación racial pues consideró inconstitucional la segregación racial en las escuelas americanas. Véase el texto de la decisión judicial en HARry W. JONES: «La Suprema Corte de los Estados Unidos. Brown contra la Junta de Educación de Topeka. 1954», en DANiel J. Boorstin (comp.), Compendio histórico de los Estados Unidos. Un recorrido por sus documentos fundamentales, Fondo de Cultura Económica, México, 1997, pp. 725-732.

34. http://www.flickr.com/photos/whitehouse/6599527897/ [1 de julio de 2013].

35. http://www.youtube.com/watch?v=BCsJ-24MdZc\&feature=player_embedded [15 de julio de 2013]. 


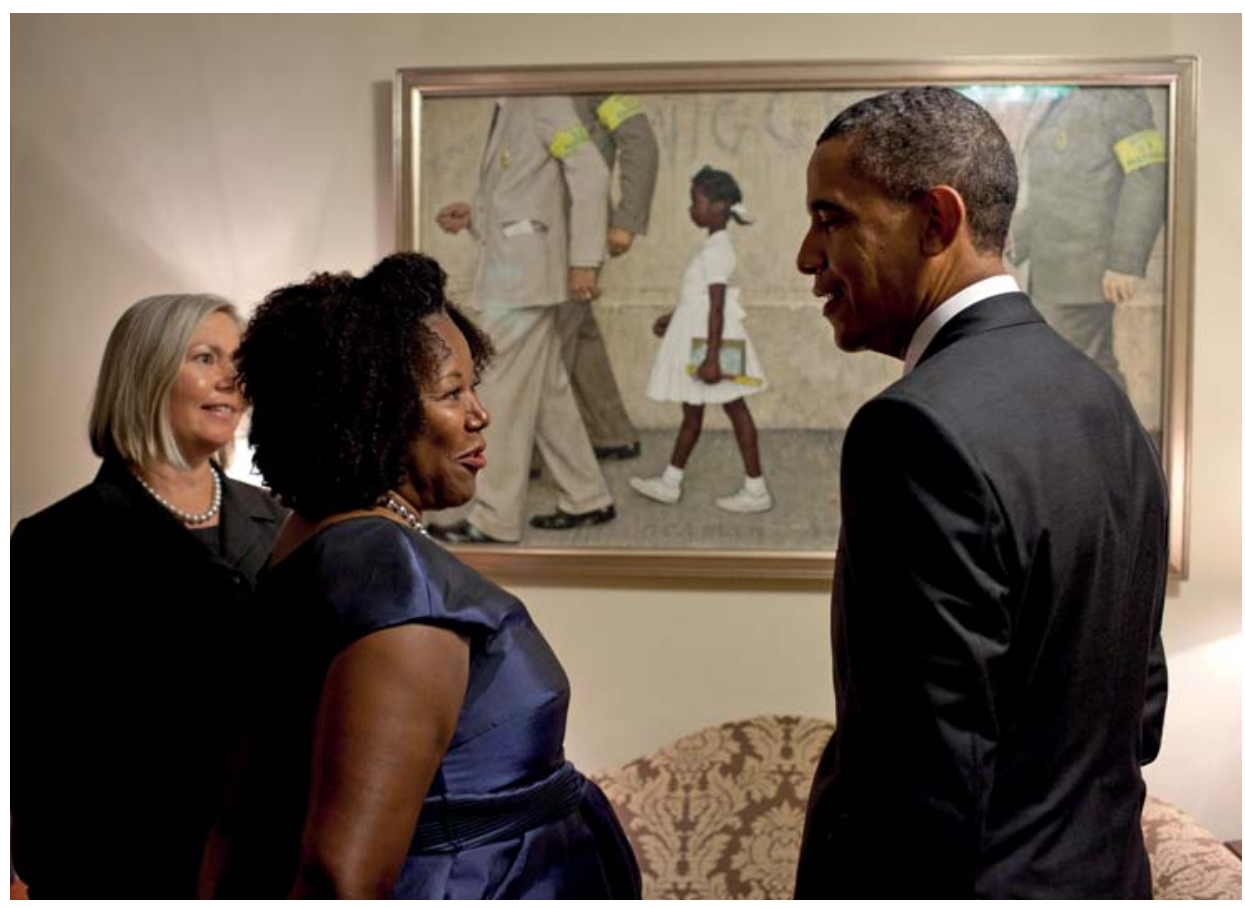

Fig. 1. Pete Souza, Barack Obama conversa con Ruby Bridges, 2011, official White House Photo

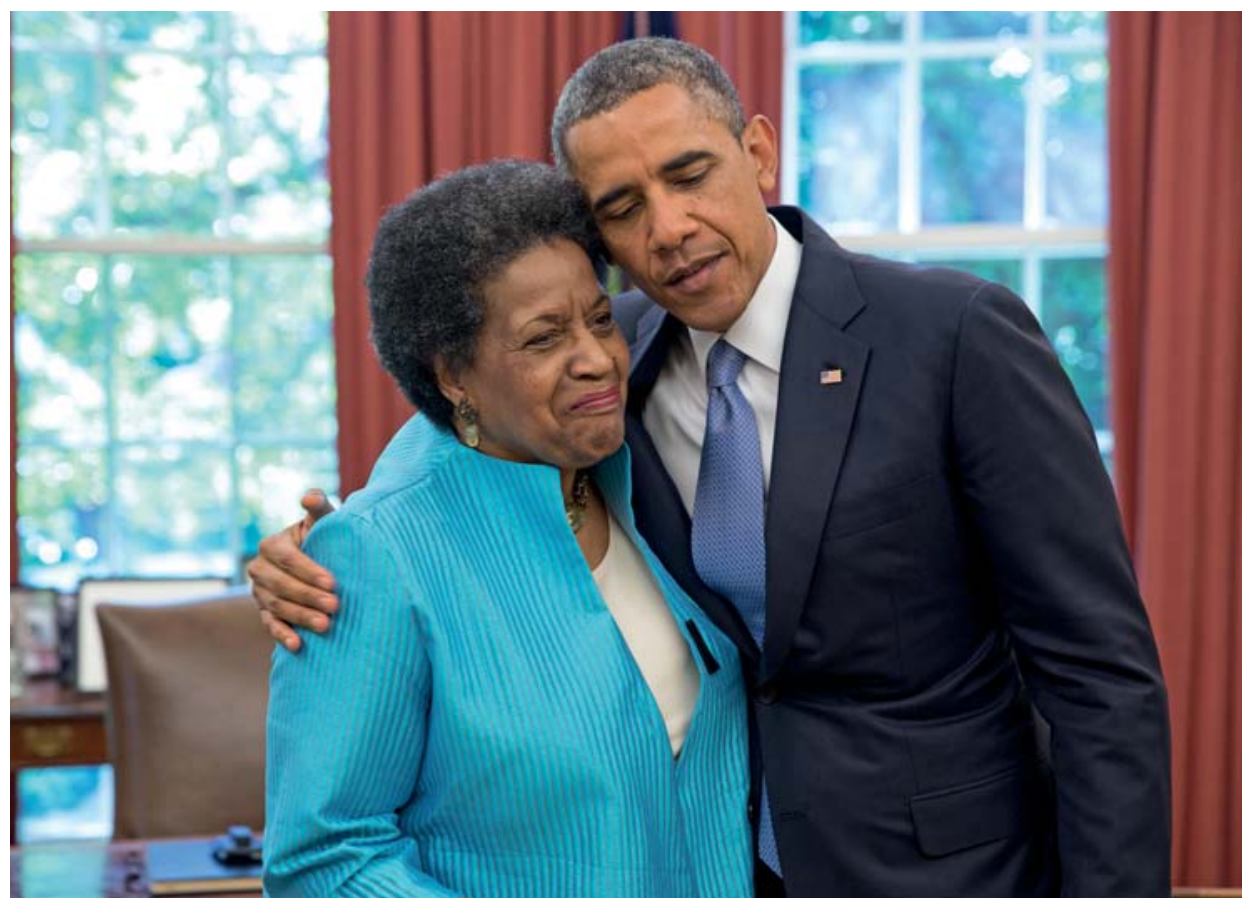

Fig. 2. Pete SouzA, Barack Obama abrazando a Myrlie Evers Williams, 2013, official White House Photo 
los derechos civiles a la figura de Obama, como si la fotografía se convirtiese en un palimpsesto sobre el que se pudiesen ver otras imágenes que forman parte de la memoria visual y que abren la puerta a la intericonicidad, ${ }^{36}$ al valor que tienen unas imágenes para remitir a otras y actualizar sus sentidos. Del mismo modo que Ruby era la primera niña negra que accedía a las escuelas de Nueva Orleans, Obama es el primer negro que accede a la Casa Blanca. Bien mirado, sus historias son paralelas y se pueden trazar puentes, sentidos y valores entre ambas imágenes, pues ambos fueron los primeros negros en acceder a espacios que eran una prerrogativa de los blancos. Ahí reside la plusvalía de la fotografía digital y la web 2.0.

Junto a Ruby Bridges, las fotografías de Flickr muestran otros temas y protagonistas de las luchas por los derechos civiles de los años sesenta que contribuyeron a crear una sociedad más igualitaria en un año, 2013, que marca el 50 aniversario de muchos de esos acontecimientos. La fotografía del 4 de junio de 2013 [Fig. 2] con Myrlie Evers Williams ${ }^{37}$ y la fotografía de 24 de mayo de 2013 [Fig. 3] con Thelma Maxine Pippen $\mathrm{McNair}^{38}$ evocan el recuerdo de las víctimas mortales de las luchas civiles. Ambas mujeres son, respectivamente,

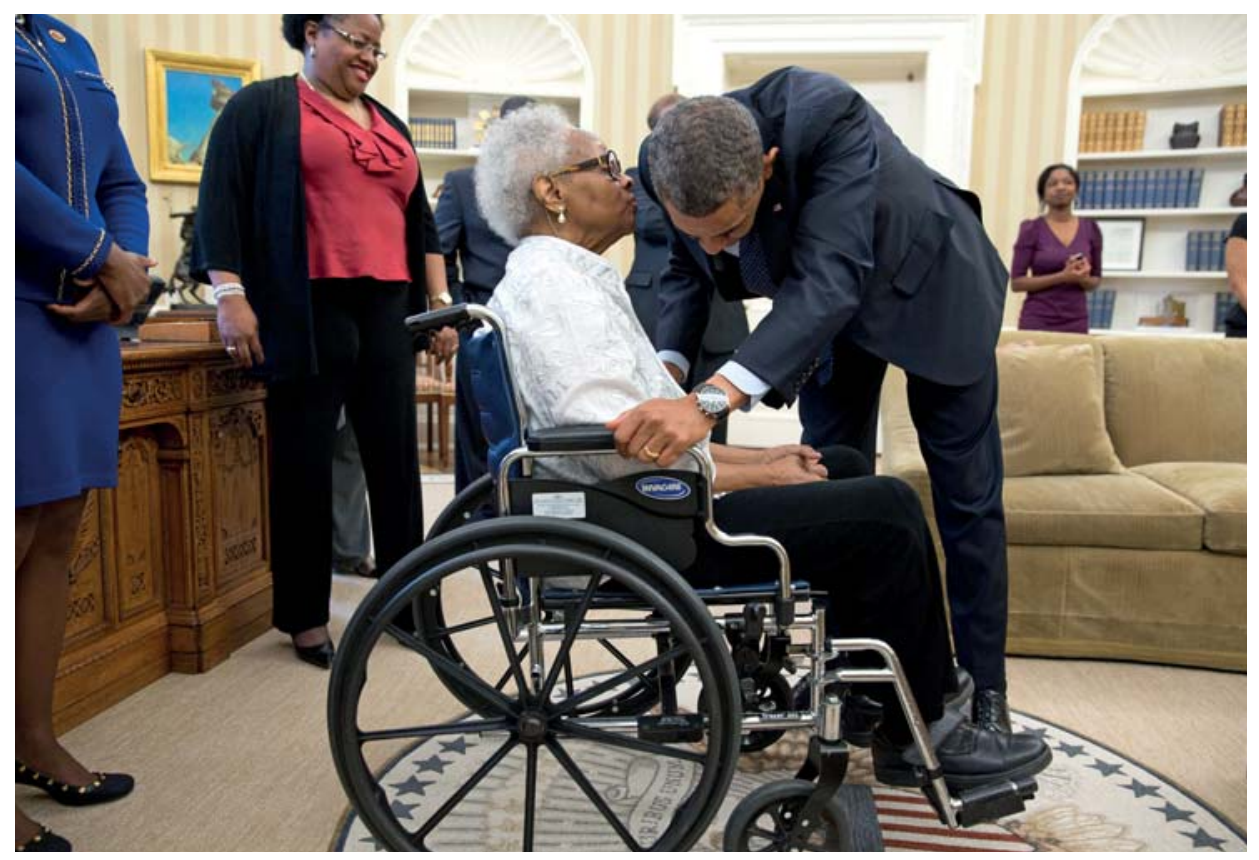

Fig. 3. Pete SouzA, Barack Obama junto a Thelma Maxine Pippen McNair, 2013, official White House Photo

36. Tomo el concepto de intericonicidad en relación con la memoria visual de los Estados Unidos de Clément Chéroux, «¿Qué hemos visto del 11 de septiembre?», en G. Didi-Huberman, C. Chéroux, J. Arnaldo: Cuando las imágenes tocan lo real, Círculo de Bellas Artes, Madrid, 2013, pp. 37-68.

37. http://www.flickr.com/photos/whitehouse/8952171039/ [1 de julio de 2013].

38. http://www.flickr.com/photos/whitehouse/9097258490/ [1 de julio de 2013]. 
la viuda de Medgar Evers y la madre de Denise McNair, ambos asesinados en 1963.

El primero se involucró en la National Association for the Advancement of Colored People (NAACP) y trabajó por la integración de los negros en la Universidad de Mississippi, siendo asesinado el 12 de junio de 1963 por Byron De La Beckwith poco después de que el presidente Kennedy pronunciase un discurso por televisión sobre los derechos civiles. Lo flagrante del caso es que hasta 1994, casi treinta años después de los acontecimientos, De La Beckwith no fue declarado culpable de asesinato. El jurado de los dos primeros juicios que tuvo que afrontar estaba formado exclusivamente por blancos y, además, fuertemente controlado por los grupos de presión blancos de Mississippi como el Ku Klux Klan o el White Citizen's Council. Hasta 1994, y con un jurado compuesto por ocho negros y cuatro blancos, De La Beckwith no fue declarado culpable de homicidio en primer grado. ${ }^{39}$

Un caso similar es el de Denise McNair y las otras tres niñas (Addie Mae Collins, Cynthia Wesley y Carole Robertson) que fueron asesinadas por la explosión de una bomba el 15 de septiembre de 1963 en la 16th Street Baptist Church de Birmingham, Alabama. Esa mañana, Bobby Frank Cherry, Thomas Blanton, Herman Frank Cash y Robert Chambliss colocaron una bomba en el sótano de la iglesia en protesta por las leyes que habían terminado con la segregación racial en las escuelas y la accionaron en el momento en que 26 niños estaban reunidos en el sótano de la iglesia preparando el oficio de ese día. La trágica muerte de las cuatro niñas fue el detonante de muchas manifestaciones y sirvió para canalizar muchas demandas a favor de los derechos civiles. El asesinato y las consecuentes protestas y reclamaciones sirvieron para que el presidente Lyndon B. Johnson firmase en 1964 la Civil Rights Act o Ley de los Derechos Civiles y, ${ }^{40}$ en 1965, la Voting Rights Act o ley que terminaba con la segregación en el voto de los afroamericanos. En este caso también hubo un considerable retraso en detener y juzgar a los culpables debido a las presiones que ejercieron los grupos supremacistas blancos. Robert Chambliss no fue declarado culpable de asesinato hasta 1977, y un año después lo fue Thomas Blanton. Frank Cash nunca fue acusado de nada, y murió en 1994, mientras que hasta el reciente 2002 no se condenó a Frank Cherry. ${ }^{41}$ Por medio de una propuesta de ley, el congreso de los Estados Unidos decidió otorgar en abril de 2013 la Medalla de Oro del Congreso, la más alta condecoración civil que se otorga en los Estados Unidos, a las cuatro niñas fallecidas en el atentado

39. http://www.nytimes.com/1994/02/08/opinion/byron-de-la-beckwith-is-guilty.html (15 de julio de 2013). Incluso el FBI pudo ocultar pruebas que implicaban directamente a los acusados. Para el papel del fBi en el caso de Medgar Evers véase Kenneth O’Reilly, «The fBi and the civil rights movement during the Kennedy years. From the freedom rides to Albany», The Journal of Southern History, 54 (1988), pp. 201-232.

40. La historia de la firma de la ley se narra en CLIFford M. LyTLE, «The history of the civil rights bill of 1964», The Journal of Negro History, 51 (1966), pp. 275-296.

41.http://www.nytimes.com/2002/05/23/opinion/belated-justice-in-birmingham.html? ref=denisemcnair [15 de julio de 2013]. 
racista. La fotografía de la cuenta de Flickr muestra a Obama después de firmar el proyecto de ley H. R. 360 por el que se entrega la condecoración y en presencia de la madre de Denise McNair. ${ }^{42}$

Obama es consciente que sin la lucha de Ruby Bridges, Medgar Evers o el fallecimiento de las cuatro niñas, él no estaría sentado en la Casa Blanca, entre otras cuestiones porque fueron acontecimientos que favorecieron la firma de la Voting Rights Act de 1965 por parte del presidente Johnson y que posibilitaba que los negros pudiesen votar sin restricciones. Las fotografías de Obama con esos mitos de las luchas por los derechos civiles son una manera de recordar sus sacrificios, pero también de recordar que la lucha no ha terminado. Precisamente, los casos de Medgar Evers y la bomba de Birmingham no han sido resueltos judicialmente hasta fechas muy recientes, lo que indica la actualidad del tema del racismo y la necesidad de cerrar heridas. Obama se muestra cariñoso, cálido y acogedor con las familias de las víctimas, casi como si él fuese un miembro más de las mismas, activando esa plusvalía de valores e intericonicidad que la imagen digital puede generar en los espectadores. La post-blackness permite a Obama identificarse con esos mitos y personajes de las luchas por los derechos civiles pero con un cuidadoso sentido de la imagen. Se han buscado imágenes respetuosas de unas tragedias que podrían engendrar sentimientos de culpabilidad entre los blancos de hoy en día. Obama opta por una puesta en escena que permite actualizar de manera edulcorada unas muertes trágicas y violentas.

Otro de los personajes relacionados con los derechos civiles y recordados de un modo cargado de intericonicidad es Rosa Parks. El 18 de abril de 2012, Barack Obama visitó el Henry Ford Museum de Deaborn, Michigan, en donde se custodia restaurado el autobús en el que Rosa Parks protagonizó su historia. ${ }^{43}$ La fotografía muestra a Obama sentado en el mismo asiento en el que años atrás Rosa Parks se sentó, mirando por la ventana de la misma manera y con el mismo gesto que la mítica activista [Fig. 4].

El rechazo de Rosa Parks a dejar su asiento del autobús a un blanco en Montgomery, Alabama, se considera el comienzo simbólico de la lucha por los derechos civiles, ${ }^{44}$ pues generó un boicot contra la segregación en los transportes públicos que encendió la chispa de la lucha en otros lugares. La historia de Rosa Parks es, además, la lucha por otro espacio simbólico y real: la

42. El contenido de la ley se puede leer en el siguiente enlace: https://www.opencongress.org/ bill/113-h360/text [15 de julio de 2013].

43. http://www.hfmgv.org/exhibits/rosaparks/home.asp [1 de julio de 2013].

44. El papel de las mujeres en este proceso ha sido analizado en LAVERnE GYANT, «Passing the torch: African American woman in the civil rights movement», Journal of Black Studies, 26 (1996), pp. 629-647. Rosa Parks no fue la primera mujer negra que se negó a ceder su asiento en los autobuses de Montgomery pues, antes que ella, dos mujeres ya lo habían hecho en 1955. E. D. Nixon, presidente de la NAACP promovió la figura de Rosa Parks ya que su caso tenía más posibilidades de ganar en los tribunales. La historia de Rosa Parks se instrumentalizó como una sólida propaganda a favor de los derechos civiles y se prescindió de las dos mujeres que también se negaron a ceder su asiento porque no eran ética ni moralmente vistas como ejemplos a seguir. Una de ellas tenía 15 años, estaba embarazada, soltera y se resistió al ser arrestada, mientras que la segunda vivía con su padre alcohólico en una chabola. Véase Berger, Seeing, p. 120. 


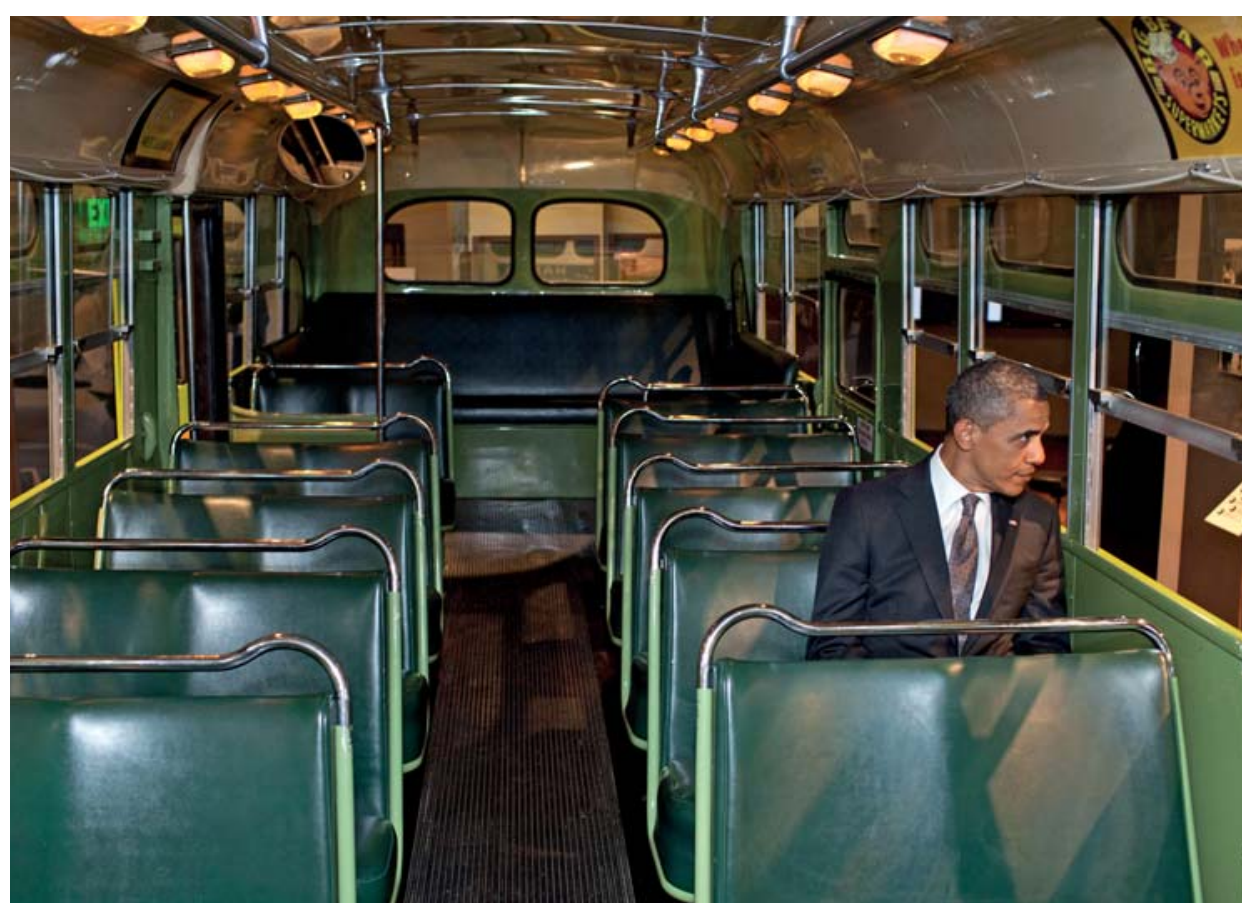

Fig. 4. Pete SouzA, Barack Obama sentado en el autobús de Rosa Parks, 2012, official White House Photo

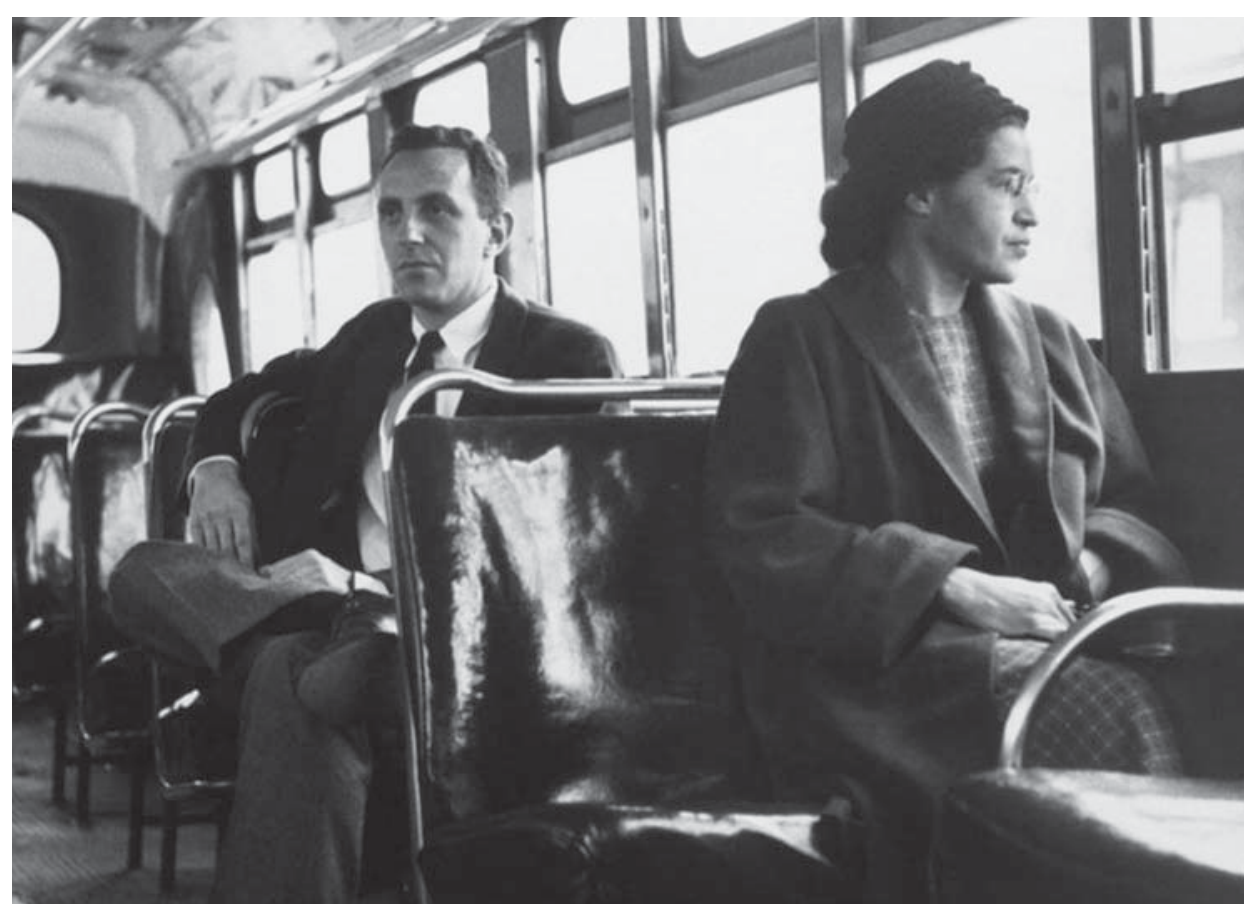

Fig. 5. Anónimo, Rosa Parks en un autobús, 1956, official White House Photo 
conquista por la igualdad en el ámbito de lo público, el de los transportes, del mismo modo que Ruby Bridges luchaba por la conquista del espacio público de las escuelas. Aunque en ambos casos era una lucha por un espacio real, también había un componente simbólico y democrático en tanto en cuanto era el uso y disfrute de servicios públicos lo que estaba en juego. ${ }^{45}$

La historia de Rosa Parks debe mucho a la fotografía ya que las imágenes de los acontecimientos contribuyeron a reforzar su lucha. Una de ellas muestra a Rosa Parks en el momento en que un policía le toma las huellas dactilares en comisaría, imagen que enfatiza el papel de víctima de Rosa Parks y que sirvió para respaldar las apelaciones de la NAACP. ${ }^{46}$ La otra es de 1956 y fue tomada cuando el boicot ya había terminado [Fig. 5].

En ella se ve a Rosa Parks en un autobús de Montgomery, sentada en uno de los asientos, delante de un blanco y mirando por la ventana. La imagen podría ser muy simbólica ya que la disposición de Rosa Parks delante del pasajero blanco podría aludir al viejo orden segregacionista que Rosa Parks había desafiado... pero el hombre blanco era un periodista llamado Nicholas Chriss que cubría para la prensa la situación en Montgomery tras el final de la segregación en los transportes públicos. La imagen se hizo tremendamente popular gracias a su inclusión en la campaña publicitaria Think different de Apple (que se distribuyó también en autobuses) y esa imagen es a la que verdaderamente remite la fotografía de Obama. ${ }^{47}$ En este caso la puesta en escena parece más cuidada, o incluso preparada, porque Obama reproduce la postura de Rosa Parks en la fotografía más difundida de su historia, lo que hace más patente el sentido de intericonicidad entre ambas imágenes. Los valores y la historia que se asocia a la imagen de Rosa Parks se trasladan a la figura de Obama, como si él fuese el protagonista de esa historia de segregación. Sin embargo, la imagen es más compleja en cuanto a los trasvases de valores y la intericonicidad, pues Rosa Parks es la única mujer cuya capilla ardiente fue instalada en el Capitolio de Washington en el año 2005, un privilegio reservado a los presidentes de los Estados Unidos. ${ }^{48}$ De este modo, Rosa Parks fue una mujer que luchó por los derechos civiles de los afroamericanos y que, al fallecer, recibió los mismos honores que un presidente. La fotografía de Obama en el mismo autobús rebosa de sentidos y significados. No solo evoca las luchas por los derechos civiles que se corporeizan en el presidente, sino que los valores de Obama se trasladan a la figura de Rosa Parks, como si la imagen estallase en sentidos hacia el pasado y el presente.

45. ZOE TRODD, «A negative utopia: protest memory and the spatio-symbolism of civil rights literature and photography», African American Review, 42 (2008), pp. 25-40.

46. Berger, Seeing, p. 27.

47. http://www.flickr.com/photos/whitehouse/6948113926/ [1 de julio de 2013].

48. Rosa Parks no fue, sin embargo, el primer afroamericano cuyo velatorio tuvo lugar bajo la cúpula del Capitolio. Este triste honor le corresponde al policía Jacob Chestnut, vigilante del Capitolio y que fue abatido a tiros junto al detective John Gibson en el ataque de un esquizofrénico al edificio en el año 1998. La lista de las capillas ardientes que se han instalado en el Capitolio se puede consultar en http://www.aoc.gov/ nations-stage/lying-state (15 de julio de 2013). 


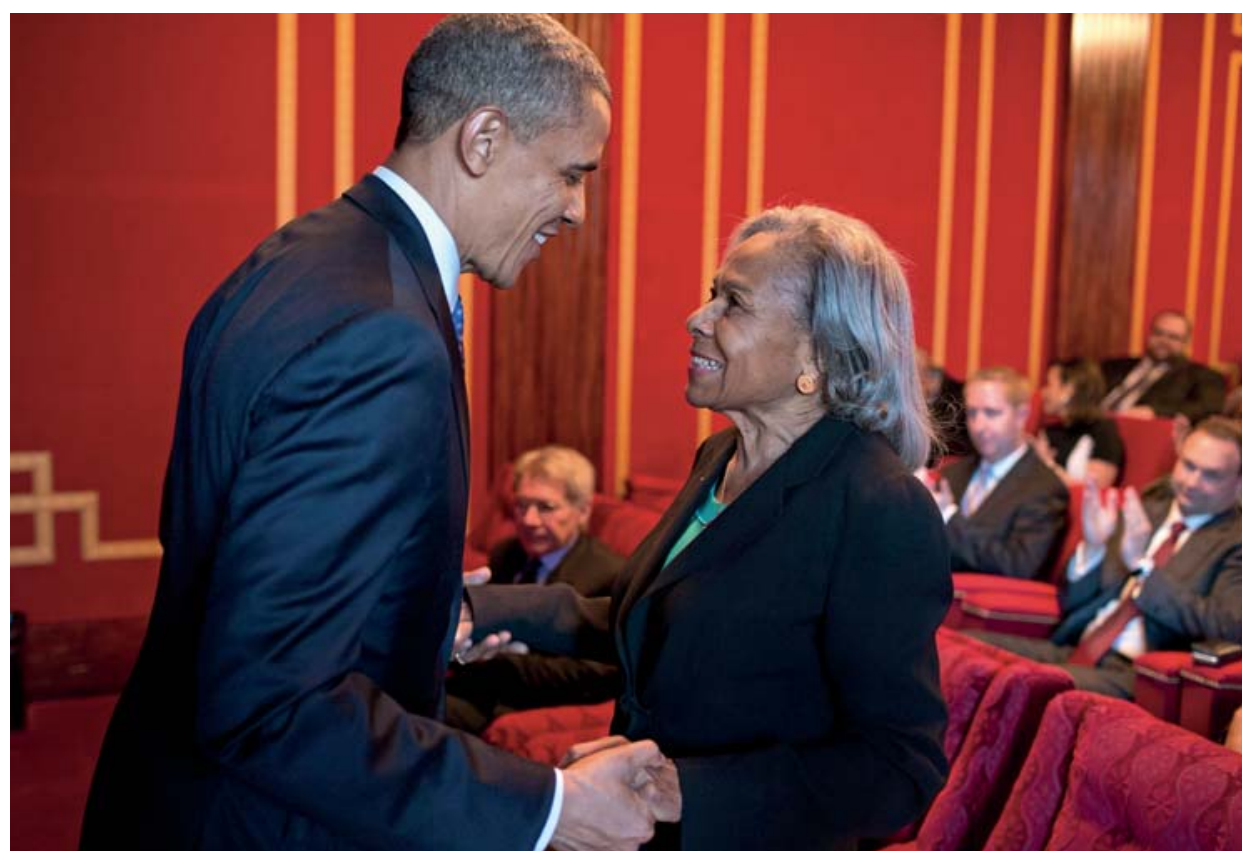

Fig. 6. Pete Souza, Barack Obama saluda a Rachel Robinson, 2013, official White House Photo

El deporte es también otro ámbito en el que los afroamericanos de los años sesenta tuvieron que luchar por romper las barreras de la segregación. Conviene recordar que la cultura estadounidense otorga un peso importante al deporte y a los deportistas, siendo un espacio en el que se reflejan tanto los valores como la propia historia del país. En el deporte convergen los tópicos del sueño americano, de la cultura del esfuerzo y del individualismo, dos de los grandes pilares del American way of life. Pero también muestra los aspectos más deleznables como la segregación racial. El mismo Obama practica baloncesto en sus ratos libres (algunas fotografías en Flickr así lo recogen), aunque también es frecuente verlo trabajando en el Despacho Oval acompañado de un balón de fútbol americano o asistiendo como comentarista a partidos de beisbol. ${ }^{49}$

Dos fotografías relacionan a Obama con las luchas de los afroamericanos en el deporte de los años sesenta. Una de ellas, tomada el 2 de abril de 2013, muestra a Obama saludando a la emocionada Rachel Robinson, viuda del famoso jugador de beisbol de los Brooklyn Dodgers, Jackie Robinson ${ }^{50}$. La fotografía está tomada en un pequeño cine privado que se encuentra en la Casa Blanca antes de que el presidente viese en primicia la película 42, acompañado de parte del reparto de la misma (se adivina a Harrison Ford entre Obama y

49. Vives-Ferrándiz, Yes we Flickr, pp. 513-514.

50. http://www.flickr.com/photos/whitehouse/8735987202/ [1 de julio de 2013]. 
Rachel Robinson) y de los familiares de Robinson, el primer jugador negro que participó en las grandes ligas y cuya historia se narra en la película que Obama se dispone a ver [Fig. 6]. El recuerdo a Jackie Robinson en la fotografía de Flickr es una pequeña oda a la historia americana y la identidad afroamericana. De nuevo, los paralelismos con Obama son más que evidentes pues del mismo modo que Robinson fue el primer negro que jugó en las grandes ligas de beisbol en 1947 [Fig. 7] y rompió con las barreras raciales de su época, ${ }^{51}$ Obama es el primer negro que se sienta en el Despacho Oval.

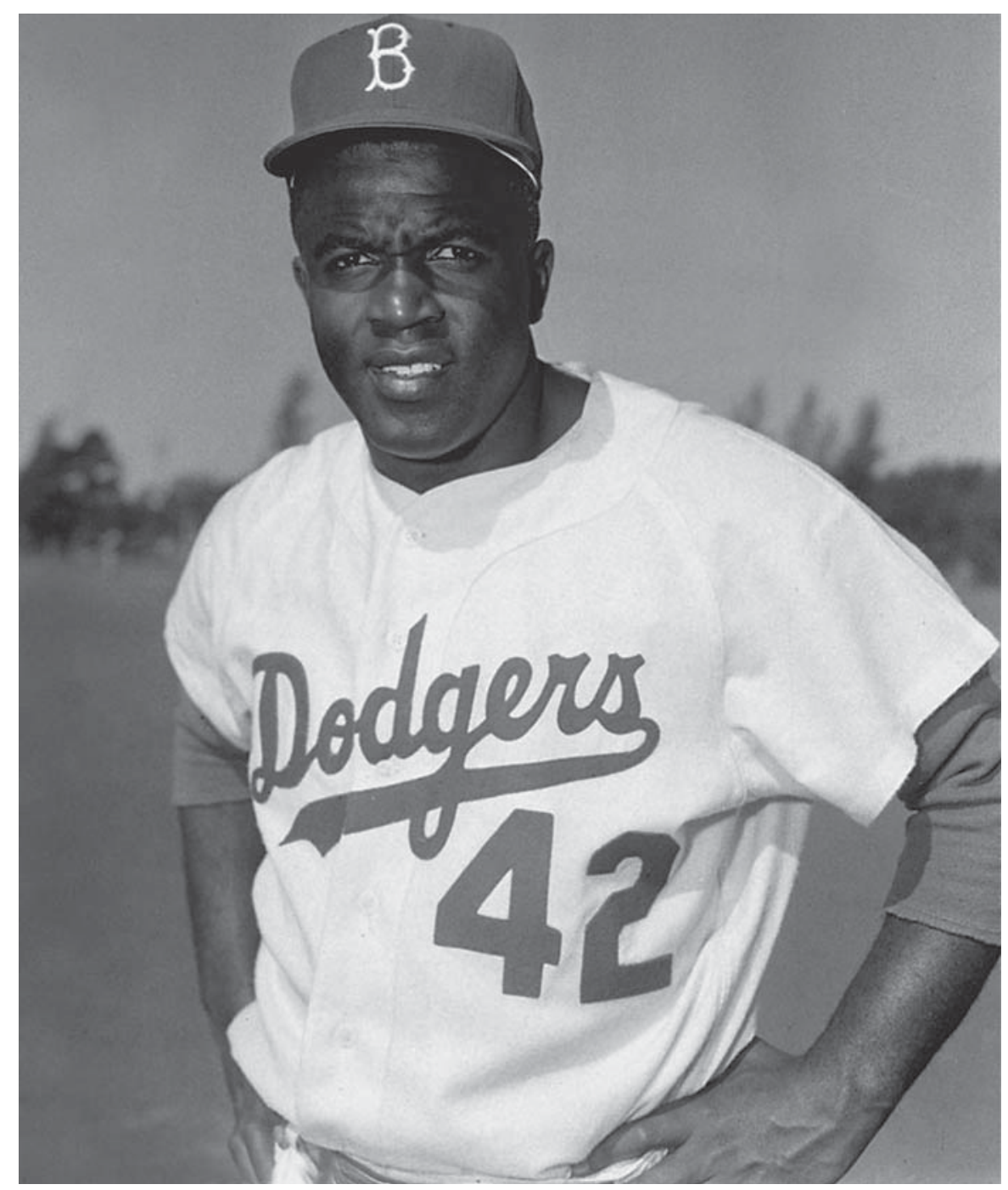

Fig. 7. Anónimo, Jackie Robinson

51. Neil J. Sullivan, «Baseball and race: the limits of competition», Journal of Negro History, 83 (1998), pp. 168-177. 
Junto al beisbol, Obama es un gran aficionado al baloncesto, siendo frecuentes las fotografías que lo retratan jugando un partido junto a sus asesores y miembros del gobierno. Recientemente, Obama ha recibido en la Casa Blanca la visita de los jugadores de los Loyola Ramblers de la Universidad de Chicago que en 1963 jugaron el llamado «partido del cambio» contra la Mississippi State University. Por primera vez en la historia de la NCAA (National Collegiate Athletics Association), un equipo alineaba a cuatro jugadores afroamericanos en su quinteto inicial y desafiaban las barreras raciales que también condicionaban el deporte. Los equipos mixtos no estaban bien vistos en Mississippi y lo habitual era que los equipos incluyesen, como mucho, a dos jugadores negros en sus filas. ${ }^{52}$ Los Loyola Ramblers desafiaron estas barreras y alinearon a cuatro jugadores negros para un partido que estuvo a punto de ser suspendido por los recelos del gobernador del estado de Mississippi. De hecho, ante estas presiones, el partido se jugó en Michigan para evitar posibles incidentes con grupos supremacistas blancos. ${ }^{53}$ Los Loyola Ramblers vencieron a un equipo integrado por blancos en un partido histórico en el que predominó el juego limpio. Antes de iniciarse, los capitanes de ambos equipos se dieron la mano en un gesto simbólico que fue inmortalizado en una célebre fotografía. La fotografía de Obama con los jugadores de los Loyola Ramblers es una imagen cuidadosamente ideológica, pues consigue emparentar a Barack Obama con los logros de esos deportistas. ${ }^{54}$ La imagen muestra a tres de los jugadores negros que formaban parte de ese equipo junto a uno de los blancos, de manera que parece que Obama formaba (o forma) parte de ese quinteto inicial que ha pasado a la historia de las luchas raciales. Además, la historia del partido de baloncesto encaja perfectamente con el discurso sobre la raza de Obama pues habla de la necesidad de aunar esfuerzos para lograr la victoria. El equipo de los Loyola Ramblers estaba formado por blancos y negros y es en esa cordialidad en la que debe asentarse la política que Obama propugna.

La armonía y espíritu de reconciliación que evidencian muchas de estas imágenes no hace olvidar las tensiones raciales que a fecha de hoy se siguen viviendo. Aunque Obama abogue por la unidad y la cooperación entre blancos y negros, la reciente muerte del joven afroamericano de 17 años Trayvon Martin en 2012 a manos de un blanco, con su posterior absolución por un jurado de mayoría blanca, ha abierto las heridas que parecían cerradas y ha puesto sobre la mesa la realidad racista de los Estados Unidos. El propio Obama expresó que él mismo (o un hijo suyo) podía haber sido en su juventud Trayvon Martin, ${ }^{55}$ una declaración muy emotiva que se considera, junto al discurso sobre el racis-

52. Para la problemática de la segregación racial en el baloncesto y en el estado de Mississippi, véase Russell J. Henderson, «The 1963 Mississipi State University controversy and the repeal of the unwritten law: something more than the game will be lost», The Journal of Southern History, 63 (1997), pp. 827-854.

53. http://www.whitehouse.gov/blog/2013/07/11/game-change-comes-white-house [Consultado el 20 de julio de 2013].

54. http://www.flickr.com/photos/whitehouse/9264985692/

55. http://internacional.elpais.com/internacional/2013/07/19/actualidad/1374258957_938532.html [20 de julio de 2013]. 
mo que pronunció en 2008, una de las declaraciones oficiales sobre la identidad afroamericana más importantes del mundo contemporáneo. ${ }^{56}$ Aunque Obama simpatiza con los afroamericanos al vincular su propia persona con los acontecimientos de Trayvon Martin, en sus declaraciones queda evidente que no olvida el papel de los blancos en estas tensiones. No en vano, en él se corporeiza la postblackness de manera palmaria al ser capaz de adaptar su sentido de identidad afroamericana a las circunstancias y a las audiencias que le escuchan. Obama alude a los desafíos que los jóvenes actuales deben afrontar en cuestiones de raza y se muestra convencido de que su aproximación al fenómeno racial es mejor que la de sus abuelos. Obama menciona, finalmente, a blancos y negros y a los esfuerzos que todos hacen por conseguir a more perfect union, una unión más perfecta, la famosa frase que encabeza el preámbulo de la Constitución americana de 1787, que Obama empleó para titular su discurso sobre la raza en 2008 y que cierra su intervención sobre la muerte de Martin. En 2013, esa more perfect union entre blancos y negros tiene que ser todavía consolidada. Ahí reside el sentido de todas esas fotografías con los mitos vivientes de las luchas raciales de los años sesenta. Citar la more perfect union supone revisitar las bases fundacionales de la cultura americana y darles un nuevo sentido cerca de 250 años después junto a las figuras primordiales de las luchas raciales. Así es como la identidad afroamericana se moldea y se customiza en la imagen digital para afrontar los desafíos raciales contemporáneos.

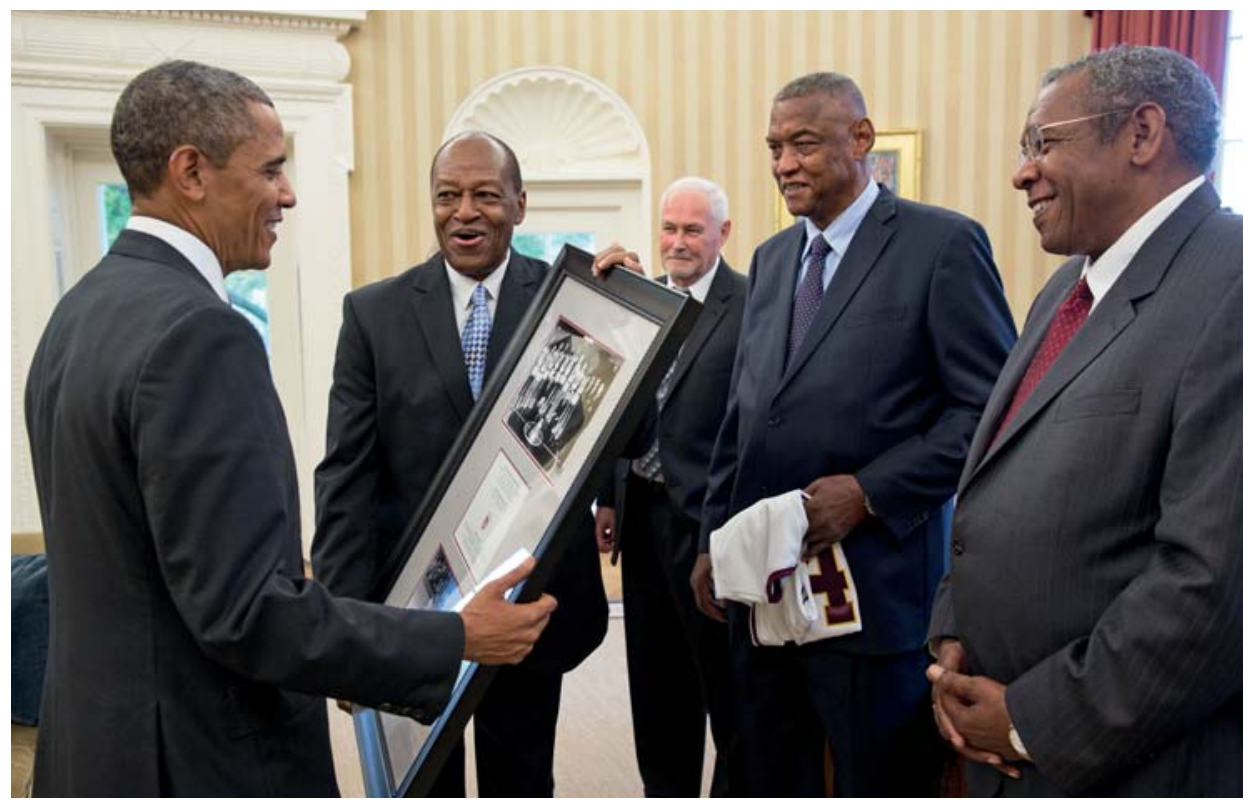

Fig. 8. Pete SouzA, Barack Obama recibe a los jugadores de los Loyola Ramblers, 2013, official White House Photo

56. http://www.youtube.com/watch?v=MHBdZWbncXI\&feature=c4-overview-vl\&list= PL8C61A61D646F0865 [20 de julio de 2013]. 